\title{
Identification of Type-specific Cytotoxic T Lymphocyte Responses to Homologous Viral Proteins in Laboratory Workers Accidentally Infected With HIV-1
}

\author{
Nikolaos V. Sipsas, ${ }^{\star}$ Spyros A. Kalams, ${ }^{\star}$ Alicja Trocha, ${ }^{\star}$ Suqin He, ${ }^{\star}$ William A. Blattner, ${ }^{\ddagger}$ Bruce D. Walker, \\ and R. Paul Johnson ${ }^{\star}$ \\ *AIDS Research Center and Infectious Disease Unit, Massachusetts General Hospital and Harvard Medical School, Charlestown, \\ Massachusetts 02129; ${ }^{\ddagger}$ Institute of Human Virology, University of Maryland Medical School, Baltimore, Maryland 21201; and ${ }^{\S}$ New \\ England Regional Primate Research Center, Harvard Medical School, Southborough, Massachusetts 01772
}

\begin{abstract}
Characterization of the cytotoxic T lymphocyte (CTL) response against HIV-1 has been limited by the use of target cells expressing viral proteins from laboratory isolates of HIV-1. This approach has favored identification of groupspecific CTL responses and precluded assessment of the extent of type-specific CTL responses directed against HIV-1. Using cells expressing viral proteins from the HIV-1 IIIB strain, we performed a detailed characterization of HIV1-specific CTL response in three laboratory workers accidentally infected with HIV-1 IIIB. Eight of the epitopes identified were group specific, lying in relatively conserved regions of Gag, reverse transcriptase, and envelope. Three type-specific epitopes were identified, two of them in highly variable regions of envelope. In longitudinal studies in one subject, seven different epitopes and five different restricting HLA class I alleles were identified, with a progressive increase in the number of CTL epitopes recognized by this subject over time. Our data demonstrate that type-specific CTL responses make up a significant proportion of the host cellular immune response against HIV-1 and that a broadening of epitope specificity may occur. (J. Clin. Invest. 1997. 99: 752-762.) Key words: human immunodeficiency virus-specific cytotoxic $\mathrm{T}$ lymphocyte $\cdot$ acquired immunodeficiency syndrome - human immunodeficiency virus-infected laboratory workers $\bullet$ immune response
\end{abstract}

\section{Introduction}

HIV-1 infection is associated with a vigorous virus-specific cytotoxic $\mathrm{T}$ lymphocyte $(\mathrm{CTL})^{1}$ response, which is mediated by

Address correspondence to Dr. R. Paul Johnson, AIDS Research Center and Infectious Disease Unit, Massachusetts General Hospital, 149 13th Street, Charlestown, MA 02129. Phone: 617-726-5772; FAX: 617-726-5411; E-mail: pjohnson@warren.med.harvard.edu

Received for publication 21 October 1996 and accepted in revised form 6 December 1996.

1. Abbreviations used in this paper: aa, amino acid; B-LCL, B-lymphoblastoid cell line; CTL, cytotoxic T lymphocyte; CTLp, CTL precursors; Env, envelope; PFA, precursor frequency assay; RT, reverse transcriptase.

J. Clin. Invest.

(C) The American Society for Clinical Investigation, Inc.

0021-9738/97/02/0752/11 \$2.00

Volume 99, Number 4, February 1997, 752-762
$\mathrm{CD}^{+}$HLA class I-restricted CTL and directed at multiple viral proteins including Gag, reverse transcriptase (RT), envelope (Env), Nef, Vif, and Tat (1). Supportive evidence for a protective role for HIV-1-specific CTL has been derived from several recent studies. In primary HIV-1 infection, the viral load declines in association with a mounting CTL response, while neutralizing antibodies emerge much later in the course of the disease, a finding suggesting that cell-mediated immunity rather than humoral immunity is involved in the initial control of viremia $(2,3)$. CTL specific for HIV-1 are able to lyse effectively HIV-1-infected cells (4) and to inhibit viral replication in vitro $(4 a)$. A vigorous virus-specific CTL response is a major component of the host immune response in long-term nonprogressors (5-7). The observation that CTL activity declines with disease progression $(7,8)$ and the demonstration of HIV-1-specific CTL activity in exposed uninfected individuals further supports a protective role for CTL $(9,10)$. These data, together with similar data from animal models in which antiviral CTL can prevent disease (11) as well as clear established infections (12), suggest that HIV-1-specific CTL are likely to have a protective activity against HIV infection.

Although there have been significant advances in our understanding of the CTL response to HIV-1, the tremendous sequence variation that occurs over the course of the infection has made it difficult to determine the full spectrum of this response to the virus. HIV-1 sequence variation in the envelope protein may approach $30 \%$ (13), and even single amino acid changes may lead to a loss of CTL recognition of variant epitopes $(14,15)$. Most studies analyzing the CTL response to HIV-1 have relied on the use of target cells expressing viral gene products of laboratory strains of HIV, which may differ substantially from the infecting strain of virus and will favor the detection of group-specific CTL responses. Approaches that do not examine recognition of autologous virus proteins are therefore likely to underestimate type-specific responses to highly variable proteins such as the Env protein.

The unfortunate infection of three laboratory workers with the IIIB strain of HIV-1 provided a unique setting in which the genotype of the infecting inoculum was known $(16,17)$. Since recombinant vaccinia vectors expressing HIV-1 IIIBderived proteins were readily available, we could analyze CTL activity in these subjects using target cells expressing homologous viral proteins. These persons have been precisely characterized with respect to humoral responses to HIV-1 (16-19), but no information has been available regarding the cellular immune response in these subjects. The aim of this study was to analyze the CTL responses using targets expressing autologous viral proteins in laboratory workers infected with the IIIB strain of HIV-1 and to identify type- and group-specific CTL responses. 


\section{Methods}

Subjects. The subjects of this study were three laboratory workers (LWF, LWR, and LWS) who were accidentally infected with the IIIB strain of HIV-1. At the time of infection, all three laboratory workers were working in facilities engaged in preparation of highly concentrated HIV-1. Sequence analysis of the envelope gene was used to confirm that the subjects were infected with the HIV-1 IIIB strain (16). Although it appears that the IIIB virus may have been derived from the Lai strain (20), there are small sequence differences between molecular clones derived from these strains. Because of these differences, and to highlight the fact that these workers were exposed to the IIIB stock, we will subsequently refer to the infecting strain of virus as HIV-1 IIIB. Subject LWF was infected in 1985, but the event that caused the infection has not been defined (21). LWF developed AIDS in 1993 as the CD4 count dropped below 200 cells $/ \mathrm{mm}^{3}$ (22) and in July 1995 the CD4 count was 190 cells $/ \mathrm{mm}^{3}$. LWR was infected in 1985, possibly because of a contaminated needle injury, and developed AIDS in 1991. Treatment with zidovudine started in June 1991 and didanosine was added in March 1992. LWR currently has a CD4 count of $<10$ cells $/ \mathrm{mm}^{3}$. Subject LWS seroconverted in 1990 after heavy skin and mucus membrane exposure to a highly concentrated preparation of HIV-1 (17). LWS has had a rapid disease progression marked by a rapidly declining CD4 count, which in February 1995 was 245 cells $/ \mathrm{mm}^{3}$. Vaccine therapy with recombinant gp160 was instituted in December 1992 or February 1993 for all three study subjects. The subjects gave written informed consent and the study was approved by the Massachusetts General Hospital and the National Institutes of Health and Human Studies Committees.

Cell lines. B-lymphoblastoid cell lines (B-LCL) were established using standard techniques (23). B-LCL were maintained in R20 culture medium consisting of RPMI 1640 obtained from Mediatech, Inc. (Herndon, VA) containing 20\% (vol/vol) heat inactivated FCS, and supplemented with L-glutamine $(2 \mathrm{mM})$, penicillin $(50 \mathrm{U} / \mathrm{ml})$, streptomycin $(50 \mu \mathrm{g} / \mathrm{ml})$, and Hepes buffer $(10 \mathrm{mM})$, all obtained from Sigma Chemical Co. (St. Louis, MO). Allogeneic B-LCL were obtained from the American Society for Histocompatibility and Immunogenetics B cell line repository (Baltimore, MD). All B-LCL were found to be free of mycoplasma infection by standard culture techniques. Cell lines transfected with class I molecules included T2-B35 transfected with B35 (24) (provided by Robert Siliciano, Johns Hopkins University, Baltimore, MD), H9-B14 transfected with B*1402 (4), and 721.221 transfected with $\mathrm{Cw} 3$ or $\mathrm{Cw} 7$ (provided by Ofer Mandeldoim, Harvard University, Cambridge, MA).

HLA typing. HLA typing was performed by Dr. Dean Mann, National Cancer Institute, National Institutes of Health (Bethesda, MD). HLA A and B alleles were identified by serologic techniques using a microcytotoxicity assay, and $\mathrm{C}$ alleles were identified by polymerase chain reaction amplification using sequence-specific primers (25).

Recombinant vaccinia viruses. Recombinant vaccinia viruses expressing the Gag, RT, and Env genes from molecular clones (BH8, BH10, PV22) derived from the HIV-1 IIIB strain were used to express viral antigens on target cells. Recombinant vaccinia viruses expressing serial truncations of the HIV-1 envelope glycoprotein (vPE $16,17,18,20,21,22)$ were constructed from the BH8 molecular clone of HIV-1 $(26,27)$. For the mapping of Env epitopes, we also used vaccinia viruses expressing serial deletions of the HIV-1 BH10 Env (vAbt 271, 299, 294, 295, 296, provided by Dr. Dennis Panicali, Therion Biologics, Cambridge, MA). The HIV-1 BH10 clone was also used to generate recombinant vaccinia viruses expressing the full length p55 Gag protein (vAbt 141) and the p17 (vAbt 228) and p24 (vAbt 286) Gag subunits (28), while the PV22 molecular clone was used to construct vaccinia vectors expressing the full length (VCF21) and serial truncations (VCF 32-37) of the HIV-1 RT protein. The recombinant vaccinia viruses New York City Board of Health $(\mathrm{NYCBH})$ not expressing retroviral genes and vSC8 expressing the Escherichia coli $\beta$-galactosidase (lacZ) gene were used as negative controls (29).
Synthetic HIV-1 peptides. Synthetic peptides corresponding to the HIV-1 envelope PV22 sequence were synthesized as previously described (15). These peptides were 25 amino acids (aa), and overlapped adjacent peptide by 8 aa. For the mapping of envelope epitopes, synthetic peptides obtained from R. Koup (Aaron Diamond AIDS Research Center, New York, NY) were also used, which corresponded to the HIV-1 envelope HXB2 sequence. Amino acids for the envelope synthetic peptides are numbered as indicated for the HXB2 sequence. Synthetic peptides corresponding to the HIV-1 p55 BH10 sequence were synthesized by Multiple Peptide Systems as previously described (30). Peptides for p17 and RT sequences consisted of peptides 25 aa in length and overlapping by 8 aa, while peptides for the p24 sequence consisted of a series of 23 peptides 22 aa in length and overlapping by 12 . Amino acids of the Gag and RT synthetic peptides were numbered according to the HIV-1 BH10 and PV22 clones, respectively. Additional smaller peptides (8-20 aa) used for the fine mapping of epitopes were obtained commercially from Chiron Mimotopes (Clayton, Australia) or were synthesized by standard f-Boc chemistry on a peptide synthesizer (432A; Applied Biosystems, Inc., Foster City, CA). All the synthetic peptides were synthesized as COOH-terminal amides and analyzed by HPLC. Lyophilized peptides prior to their use were dissolved at a concentration of $2 \mathrm{mg} / \mathrm{ml}$ in sterile distilled water with $10 \%$ DMSO. Peptides containing cysteine, tryptophane, or methionine residues were dissolved in the above solution with $1 \mathrm{mM}$ DTT. DMSO and DTT were obtained from Sigma Chemical Co. (St. Louis, MO).

Cytotoxicity assay. Target cells expressing HIV-1 proteins were prepared by incubating $2-5 \times 10^{6} \mathrm{~B}$-LCL in log-phase growth with 1-3 plaque forming units per cell of recombinant vaccinia viruses for $16 \mathrm{~h}$ at $37^{\circ} \mathrm{C}$ in a $5 \% \mathrm{CO}_{2}$ humidified atmosphere. Cells were then washed and labeled with $50 \mu \mathrm{Ci}$ of $\mathrm{Na}_{2}\left({ }^{51} \mathrm{CrO}_{4}\right)$, obtained from New England Nuclear (North Billerica, MA), for 90 min, and then washed again three times in R10 culture medium consisting of RPMI 1690 supplemented with $10 \%$ ( $\mathrm{vol} / \mathrm{vol}$ ) FCS. Alternatively, B-LCL were incubated with the relevant peptide at $0.2-2 \mathrm{mg} / \mathrm{ml}$ for $60 \mathrm{~min}$ during ${ }^{51} \mathrm{Cr}$ labeling, and then washed three times in R10 culture medium. Cytolytic activity was determined in a standard ${ }^{51} \mathrm{Cr}$ release assay as previously described (31). Briefly, PBMC or CTL clones (effector cells) were added to round-bottom microplate wells containing $10^{4}$

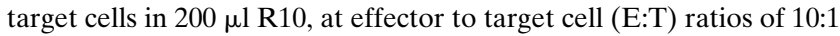
and 5:1. All assays were performed in duplicate. Plates were incubated in a humidified incubator at $37^{\circ} \mathrm{C}$ for $4 \mathrm{~h}$. Supernatants were then harvested, inactivated with detergent (5\% Triton), obtained from Sigma Chemical Co. and counted on a COBRA gamma counter, obtained from Packard Instruments Co., Inc. (Meriden, CT), and percent lysis was calculated with the formula percent lysis $=100 \times$ [(experimental release - spontaneous release)/(maximum release spontaneous release)]. Maximum release was determined by lysis of target cells by $1 \%$ Triton. Spontaneous release was $<30 \%$ for all reported assays.

For antigen-specific stimulation of effector cells, cryopreserved or fresh PBMC $\left(10^{6}\right.$ cells) were incubated in $10 \mathrm{ml}$ of R10 culture medium containing 3-5 $\times 10^{6}$ autologous B-LCL infected with a vaccinia vector expressing the $g a g$, pol, and env HIV-1 genes, and inactivated with psoralen and ultraviolet (UV) light, as previously described (32), together with $20 \times 10^{6}$ allogeneic irradiated human PBMC as feeder cells. The next day, $10 \mathrm{ml}$ of R10 medium supplemented with human rIL-2 obtained from Hofmann-LaRoche (Nutley, NJ) at a final concentration of $100 \mathrm{U} / \mathrm{ml}$ (R10-100) were added. 2 wk later, cytolytic activity was determined using a standard ${ }^{51} \mathrm{Cr}$ release assay with unlabeled autologous B-LCL infected with vaccinia NYCBH as cold targets (cold/hot targets: 20/1).

Limiting dilution precursor frequency analysis of HIV-1-specific $C T L$. To quantitate CTL responses, we used limiting dilution precursor frequency analysis (PFA) as previously described (33). Briefly, cryopreserved or fresh PBMC obtained by separation on Ficoll-sodium diatrizoate (Histopaque 1077) purchased from Sigma Chemical Co. were seeded at 500-25,000 cells per well in 24 replicate wells of 96- 
well microtiter plates in the presence of $100 \mu$ l of R10. In each well were added $2.5 \times 10^{4}$ irradiated (3,000 rads) PBMC from an HIV-1 seronegative donor (feeder cells), as well as 3-4 × $10^{4}$ autologous B-LCL infected with a recombinant vaccinia vector expressing the HIV-1 gag, pol, and env genes. Prior to use, vaccinia-infected B-LCL were inactivated using psoralen/UV light. The next day, $100 \mu \mathrm{l}$ of R10 culture media supplemented with rIL-2 (R10-100) were added. On day 14, wells were split and tested for HIV-1-specific cytolytic activity using as targets autologous ${ }^{51} \mathrm{Cr}$-labeled B-LCL infected with recombinant vaccinia viruses expressing the HIV-1 gag, pol, or env genes, as well as a control vaccinia virus. To reduce background activity, we used cold target inhibition, adding unlabeled autologous B-LCL infected with control vaccinia (cold targets) to each well at a ratio of 20:1 cold:hot B-LCL. Wells for which lysis exceeded the mean plus three standard deviations of the spontaneous release of the 24 control wells were scored as positive. The fraction of nonresponding wells was calculated for each dilution and precursor cell frequency was estimated by the maximum likelihood method (34) using software developed by S.A. Kalams.

Limiting dilution precursor frequency analysis of EBV-specific $C T L$. The same experimental conditions as above were used to assess the frequency of EBV-specific CTL precursors (CTLp) in subject LWF. Cryopreserved PBMC were stimulated with autologous irradiated $(10,000$ rads $)$ B-LCL, and 2 wk later autologous ${ }^{51} \mathrm{Cr}$-labeled B-LCL with or without cold targets were used as targets. A completely HLA-mismatched B-LCL was used as control again with or without cold targets. To reduce background lysis due to natural killer cells, unlabeled K562 cells were added at a cold/hot target ratio of 20:1.

Isolation of HIV-1-specific CTL clones and epitope mapping. T lymphocytes were derived from the wells of the PFA plates demonstrating high activity against HIV-1 antigens or from bulk effector cells after antigen-specific stimulation. The lymphocytes were seeded at 10 ,
3 , and 1 cells per well in 96-well U-bottom plates in $200 \mu \mathrm{l}$ of R10-100 culture medium containing $10^{5}$ irradiated allogeneic feeder cells. To stimulate $\mathrm{T}$ cell proliferation, we used either a CD3-specific monoclonal antibody (12F6) (35) at $0.1 \mu \mathrm{g} / \mathrm{ml}$ (polyclonal stimulation) or autologous B-LCL infected with the appropriate vaccinia vector and inactivated with psoralen/UV light, at $10^{4}$ cells per well (antigen-specific stimulation). $T$ cell clones were then expanded, screened for cytolytic activity, and maintained as previously described (36). Mapping of CTL epitopes recognized by these clones was performed using autologous B-LCL infected with recombinant vaccinia viruses expressing serial truncations of HIV-1 genes, and then autologous B-LCL pulsed with overlapping synthetic HIV-1 synthetic peptides, as previously described (15). Finally, fine mapping of the epitopes was performed using peptide titration assays as previously described (14).

\section{Results}

Isolation and characterization of HIV-specific CTL clones recognizing autologous viral sequences

To define the spectrum of epitopes recognized by HIV-1-specific CTL using autologous viral proteins, we characterized the epitope specificity and HLA restriction of a panel of CTL clones obtained from the three infected laboratory workers (Tables I and II). Using previously described techniques (37), we generated and then analyzed a total of $65 \mathrm{CD} 8^{+}$HIV-1-specific CTL clones recognizing 11 different epitopes in the Gag, RT, and Env sequences (Table I).

Subject LWF. CTL clones from subject LWF recognized a total of seven different epitopes in Gag, RT, and Env. Two Gag epitopes were identified, one in the p24 subunit and the

Table I. Epitopes Recognized by CTL Clones Isolated from Subjects LWF, LWR, and LWS

\begin{tabular}{|c|c|c|c|c|c|c|c|c|c|}
\hline \multirow[b]{2}{*}{ Subject } & \multirow[b]{2}{*}{$\begin{array}{l}\text { Representative } \\
\text { clone }\end{array}$} & \multirow[b]{2}{*}{$\begin{array}{l}\text { No. of } \\
\text { clones }\end{array}$} & \multirow[b]{2}{*}{$\begin{array}{l}\text { Time } \\
\text { points }\end{array}$} & \multicolumn{4}{|c|}{ Percent lysis* } & \multirow[b]{2}{*}{$\begin{array}{c}\text { Epitope } \\
\text { specificity }\end{array}$} & \multirow[b]{2}{*}{ Optimal epitope $e^{\S}$} \\
\hline & & & & lac & Gag & RT & Env & & \\
\hline \multirow[t]{17}{*}{ LWF } & A1 & 5 & $2 / 90$ & 5 & 49 & 3 & 2 & p24/349-359 & ACQGVGGPGGHK \\
\hline & & 1 & $9 / 92$ & & & & & & \\
\hline & & 1 & $3 / 95$ & & & & & & \\
\hline & $\mathrm{I} 11$ & 4 & $2 / 90$ & 3 & 41 & 2 & 0 & p17/77-85 & SLYNTVATL \\
\hline & & 1 & $3 / 91$ & & & & & & \\
\hline & & 1 & $11 / 91$ & & & & & & \\
\hline & & 1 & $8 / 92$ & & & & & & \\
\hline & B9 & 1 & $3 / 91$ & 1 & 0 & 0 & 57 & gp41/584-592 & ERYLKDQQL \\
\hline & & 2 & $11 / 91$ & & & & & & \\
\hline & & 1 & $8 / 92$ & & & & & & \\
\hline & & 1 & $1 / 93$ & & & & & & \\
\hline & A4 & 4 & $2 / 90$ & 12 & 10 & 49 & 7 & $\mathrm{RT} / 273-282$ & VPLDEDFRKY \\
\hline & & 1 & $3 / 95$ & & & & & & \\
\hline & $\mathrm{C} 29$ & 1 & $3 / 95$ & 0 & 0 & 32 & 0 & RT/328-336 & NPDIVIYQY \\
\hline & A5 & 2 & $3 / 95$ & 10 & 8 & 8 & 53 & gp120/156-165 & NCSFNISTSI \\
\hline & FE2 & 1 & $1 / 88$ & 0 & 2 & 4 & 39 & gp120/241-249 & CTNVSTVQC \\
\hline & & 3 & $2 / 90$ & & & & & & \\
\hline \multirow[t]{2}{*}{ LWR } & W4 & 1 & $10 / 90$ & 5 & 54 & 10 & 14 & $\mathrm{p} 24 / 215-223$ & VHPVHAGPIA \\
\hline & & 6 & $1 / 95$ & & & & & & \\
\hline \multirow[t]{4}{*}{ LWS } & SE10 & 20 & $10 / 90$ & 0 & 0 & 1 & 68 & gp41/557-565 & RAIEAQQHL \\
\hline & SR9 & 5 & $10 / 90$ & 0 & 2 & 46 & 2 & $\mathrm{RT} / 231-238$ & TAFTIPSI \\
\hline & SE18 & 1 & $10 / 90$ & 6 & 2 & 4 & 66 & gp120/2-10 & RVKEKYQHL \\
\hline & & 1 & $3 / 93$ & & & & & & \\
\hline
\end{tabular}

*Effector to target ratio of 10:1. *Epitope specificity is defined with respect to the HIV-1 protein recognized and the amino acid coordinate of the optimal epitope. ${ }^{\S}$ Optimal epitope as defined by peptide titration assays using a panel of peptides of varying length. 


\begin{tabular}{|c|c|c|c|c|c|c|c|}
\hline \multirow[b]{2}{*}{ Subject } & \multirow[b]{2}{*}{$\begin{array}{l}\text { Representative } \\
\text { clone }\end{array}$} & \multirow[b]{2}{*}{$\begin{array}{c}\text { Clone } \\
\text { specificity }\end{array}$} & \multirow[b]{2}{*}{$\begin{array}{l}\text { Epitope } \\
\text { sequence }\end{array}$} & \multirow[b]{2}{*}{$\begin{array}{l}\text { HLA } \\
\text { restriction }\end{array}$} & \multicolumn{3}{|c|}{ HIV-specific lysis* } \\
\hline & & & & & $\begin{array}{c}\text { Autologous } \\
\text { B-LCL }\end{array}$ & $\begin{array}{c}\text { HLA } \\
\text { matched }^{\ddagger}\end{array}$ & $\begin{array}{c}\text { HLA } \\
\text { mismatched }\end{array}$ \\
\hline \multicolumn{8}{|l|}{ LWF } \\
\hline & $\mathrm{A} 1$ & p24/349-359 & ACQGVGGPGGHK & A11 & 85 & 78 & 0 \\
\hline & K5 & p17/77-85 & SLYNTVATL & A2 & 56 & 26 & 0 \\
\hline & B9 & gp41/584-592 & ERYLKDQQL & B14 & 25 & 25 & 0 \\
\hline & A5 & gp120/156-165 & NCSFNISTSI & Cw8 & 68 & 60 & $6^{\S}$ \\
\hline & FE2 & gp120/241-249 & CTNVSTVQC & Cw8 & 69 & 48 & $3^{\S}$ \\
\hline & A4 & $\mathrm{RT} / 273-282$ & VPLDEDFRKY & B35 & 61 & 69 & 6 \\
\hline & $\mathrm{C} 29$ & RT/328-386 & NPDIVIYQY & B35 & 95 & 94 & 7 \\
\hline \multicolumn{8}{|l|}{ LWS } \\
\hline & SE10 & gp41/557-565 & RAIEAQQHL & B51 & 74 & 89 & 0 \\
\hline & SE18 & gp120/2-10 & RVKEKYQHL & B8 & 95 & 83 & 4 \\
\hline & SR9 & $\mathrm{RT} / 231-238$ & TAFTIPSI & B51 & 94 & 89 & 0 \\
\hline \multicolumn{8}{|l|}{ LWR } \\
\hline & W4 & p24/215-223 & VHPVHAGPIA & B55 & 64 & $64^{\|}$ & 0 \\
\hline
\end{tabular}

*HIV-1-specific lysis using an effector-to-target ratio of 10:1 of indicated target cells sensitized with peptides or infected with vaccinia vectors. HIVspecific lysis was calculated by subtracting lysis of control target cells from lysis of target cells expressing HIV antigens. ${ }^{\ddagger}$ Allogeneic target cells were matched at only a single allele unless otherwise indicated. ${ }^{\$}$ Percent lysis of the H9 T cell line transfected with the B14 allele. "Percent lysis of a B55, Cw3, Cw7 B-LCL. No lysis was observed of peptide-sensitized target cells matched at only Cw3 or Cw7.

other in the p17 subunit of Gag. In p24, a previously unreported HLA-A11-restricted epitope was recognized by seven different $\mathrm{CD}^{+}$CTL clones isolated from subject LWF at three different time points. Peptide titration assays defined an 11 amino acid peptide (ACQGVGGPGHK, aa 349-359) as the optimal epitope recognized by these clones (Fig. 1). This epitope corresponded to the proposed motif for HLA-A11 binding peptides containing a lysine at the $\mathrm{COOH}$-terminal residue and a cysteine at position $2(38,39)$. The previously reported HLA-A2-restricted p17 epitope, SLYNTAVL (aa 77-

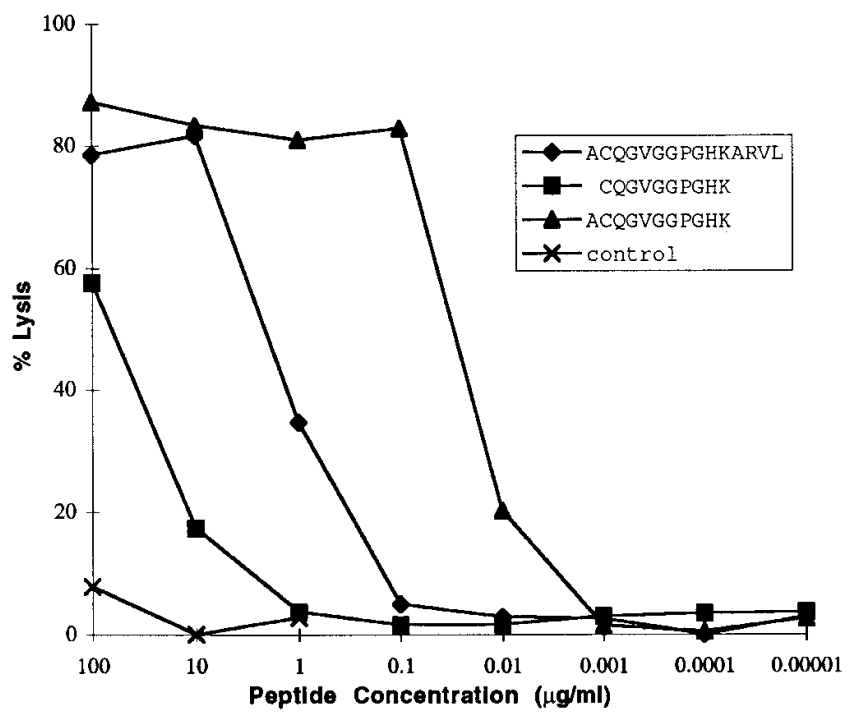

Figure 1. Definition of the optimal epitope for the HLA-A11-restricted CTL clone LWF A1. ${ }^{51} \mathrm{Cr}$-labeled B-LCL were incubated with peptides at the indicated concentrations for $60 \mathrm{~min}$, and then effector cells were added at an effector/target ratio of 10:1. The control peptide consisted of the HIV-1 RT peptide ILKEPVHGV.
85) $(36,40)$, was recognized by six $\mathrm{CD}^{+}$CTL clones isolated from subject LWF at four different time points.

Two different previously reported $(9,41)$ CTL epitopes were identified in RT (Table I). The majority of RT-specific clones from subject LWF recognized the optimal epitope VPLDEDFRKY (aa 273-282), while one clone specific for the epitope NPDIVIYQY (aa 328-336) was isolated. Interestingly, the five $\mathrm{COOH}$-terminal amino acids of this epitope overlap with a previously reported HLA-A2-restricted RT epitope (VIYQYMDDL, aa 332-340) that contains the active catalytic site for the RT protein (YMDD) (42). Although the epitope VPLDEDFRKY (aa 273-282) lies in a relatively conserved region of RT, it contains a glutamic acid instead of lysine at residue 277 , a substitution that has been reported in only one clade B strain other than IIIB and Lai (13). All of the RT-specific clones were HLA-B35 restricted, as shown by the lysis of peptide-sensitized allogeneic B-LCL matched at HLAB35 as well as the T2-B35 cell line (Table II and data not shown). Both of these epitopes fit the predicted motif for HLA-B35-restricted epitopes, containing a proline at position 2 and a tyrosine at the $\mathrm{COOH}$ terminus (43).

Epitope mapping resulted in identification of three Env epitopes, one in gp41 and two new epitopes in gp120. Five HLA-B14-restricted CD8 ${ }^{+}$CTL clones isolated from subject LWF at four different time points recognized a previously reported epitope in gp41 (ERYLKDQQL, aa 584-592) $(15,44)$. The gp120 epitope CTNVSTVQC, aa 241-249, was recognized by four CTL clones isolated from subject LWF at two different time points. The gp120 epitope is likely to be HLA-Cw8 restricted, since the representative clone LWF FE2 was able to lyse several B-LCL expressing both the B14 and Cw8 alleles, but failed to lyse H9 cells transfected with HLA-B14 (Table II). The third mapped Env epitope was a type-specific epitope in gp120 (NCSFNISTSI, aa 156-165), likewise presumed to be restricted by $\mathrm{Cw} 8$ and described in detail below. 
Subject $L W R$. All seven $\mathrm{CD} 8^{+}$CTL clones isolated from subject LWR at two different time points recognized a single epitope in p24, VHPVHAGPIA, aa 215-223. The representative clone LWR W4 was screened against a series of HLAmatched B-LCL and lysed only a line sharing the alleles B55, $\mathrm{Cw} 3$, and $\mathrm{Cw} 7$ (Table II). This clone was not able to lyse peptide-sensitized 721.221 cells transfected with either $\mathrm{Cw} 3$ or Cw7 and is likely to be HLA-B55 restricted.

Subject LWS. CTL clones from subject LWS recognized three previously unreported epitopes, one in RT and two in Env. The RT epitope, (TAFTIPSI, aa 557-565), was recognized by five $\mathrm{CD}^{+}$CTL clones isolated from subject LWS at one single time point. Representative clone LWS SR9 recognized three different peptide-sensitized HLA-B51-matched B-LCL. The optimal epitope fits the HLA-B51 motif containing an isoleucine at the $\mathrm{COOH}$ terminus and alanine at position 2 (45).

The gp41 epitope, RAIEAQQHL, aa 557-565, was recognized by $20 \mathrm{CD} 8^{+}$CTL clones isolated from subject LWS at a single time point. Although the epitope fits the HLA-B51 motif featuring a $\mathrm{COOH}$-terminal leucine and an alanine at position 2 as anchor residues, the representative clone SE10 lysed one B51-matched B-LCL but failed to lyse four other B51 ${ }^{+}$ B-LCL, possibly because of polymorphism of the B51 allele (46). The second Env epitope mapped from subject LWS was a type-specific epitope in gp120, (RVKEKYQHL, aa 2-10) described below.

\section{Identification of two type-specific CTL epitopes in highly} variable regions of gp120

The unique opportunity to use target cells expressing viral antigens representing the infecting strain of HIV-1 allowed the isolation and characterization of $\mathrm{CD}^{+} \mathrm{CTL}$ clones targeting two type-specific epitopes in highly variable regions of the gp120 protein. The gp120 RVKEKYQHL epitope was recognized by two $\mathrm{CD} 8^{+} \mathrm{CTL}$ clones derived from subject LWS at two different time points. This epitope, which is contained in the envelope leader sequence, is unique for the IIIB and Lai

Table III. Recognition of Naturally Occurring Sequence Variants by CTL Clones

\begin{tabular}{|c|c|c|c|c|c|c|}
\hline Clone & Specificity & HLA restriction & Epitope sequence & Strain & Maximal lysis* & $\mathrm{SD}_{50^{*}}$ \\
\hline & & & & & & $\mu g / m l$ \\
\hline \multirow[t]{2}{*}{ LWF A1 } & $\mathrm{p} 24 / 349-359$ & A11 & A C Q G V G G P GHK & IIIB & 94 & 0.1 \\
\hline & & & $-------\mathrm{S}--$ & RF & 89 & nd \\
\hline \multirow[t]{3}{*}{ LWF K5 } & p17/77-85 & A2 & S L Y N T V A T L & IIIB & 94 & $0.0005^{\S}$ \\
\hline & & & $-------\mathrm{V}-$ & MANC & 74 & $0.0005^{\S}$ \\
\hline & & & $--\mathrm{F}----\mathrm{V}-$ & NY5CG & 78 & $0.0005^{\S}$ \\
\hline \multirow[t]{3}{*}{ LWF A4 } & $\mathrm{RT} / 273-282$ & B35 & V P L D E D F R K Y & IIIB & 83 & 0.0001 \\
\hline & & & $----\mathrm{K}-----$ & $\mathrm{MN}$ & 2 & na \\
\hline & & & $--\mathrm{H}------$ & YU2 & 14 & na \\
\hline \multirow[t]{4}{*}{ LWF C29 } & $\mathrm{RT} / 328-336$ & B35 & N P D I V I Y Q Y & IIIB & 96 & 0.00001 \\
\hline & & & ---- I ---- & JRCSF & 87 & 0.001 \\
\hline & & & $--\mathrm{E}-----$ & JRU2RF & 97 & 0.01 \\
\hline & & & $---\mathrm{L}----$ & & 88 & 0.01 \\
\hline \multirow[t]{2}{*}{ LWF A5 } & gp120/156-165 & Cw8 & NCS F N I S T S I & IIIB & 73 & 100 \\
\hline & & & $------\mathrm{T}---$ & $\mathrm{MN}$ & 2 & na \\
\hline \multirow[t]{3}{*}{ LWF FE2 } & gp120/241-249 & Cw8 & C T N V S T V Q C & IIIB & 49 & 100 \\
\hline & & & $-\mathrm{K}-------$ & $\mathrm{MN}$ & nd & nd \\
\hline & & & $-\mathrm{R}------$ & BWBIIA & nd & nd \\
\hline \multirow[t]{5}{*}{ LWR W4 } & $\mathrm{p} 24 / 215-223$ & B55 & VH P VHAG P I A & IIIB & 87 & 0.01 \\
\hline & & & $\mathrm{L}------\mathrm{V}-$ & PH136 & 81 & 1 \\
\hline & & & $\mathrm{L}--------$ & $\mathrm{RF}$ & 88 & 0.1 \\
\hline & & & $\mathrm{L}------\mathrm{T}$ & $\mathrm{MN}$ & 62 & 0.01 \\
\hline & & & $\mathrm{L}--\mathrm{AQ}----$ & JH3 & 85 & 100 \\
\hline \multirow[t]{5}{*}{ LWS SE10 } & gp41/557-565 & B51 & R A I E A Q QH L & IIIB & 98 & 0.01 \\
\hline & & & $\mathrm{K}-------$ & NY5CG & 87 & 0.1 \\
\hline & & & $--------\mathrm{M}$ & JRCSF & 89 & 0.1 \\
\hline & & & $---\mathrm{D}-----$ & ETR & 83 & 10 \\
\hline & & & $---\mathrm{K}----$ & $\mathrm{CDC} 42$ & 85 & 10 \\
\hline \multirow[t]{4}{*}{ LWS SR9 } & $\mathrm{RT} / 231-238$ & B51 & T A F T I P S I & IIIB & 83 & 0.1 \\
\hline & & & $------\mathrm{T}$ & CAM1 & 92 & 10 \\
\hline & & & $-------\mathrm{V}$ & VE1RT & 100 & 1 \\
\hline & & & $-\mathrm{V}------$ & MANC & 38 & 100 \\
\hline \multirow[t]{2}{*}{ LWS SE18 } & gp120/2-10 & B8 & R VKE . . . K Y Q H L & IIIB & 85 & 1 \\
\hline & & & --- G I RKN ---- & JRCSF & 0 & na \\
\hline
\end{tabular}

*Refers to percent lysis of targets sensitized with the indicated peptide at $100 \mu \mathrm{g} / \mathrm{ml}$. ${ }^{*} \mathrm{SD}_{50}$ (sensitizing dose $50 \%$ ) indicates the peptide concentration that is able to sensitize target cells for $50 \%$ of maximal lysis. For peptides that were only recognized at the highest peptide concentration tested, the $\mathrm{SD}_{50}$ is indicated as $100 \mu \mathrm{g} / \mathrm{ml}$. ${ }^{8}$ The lowest peptide concentration tested. na, not applicable; nd, not done. 
strains in that it contains between positions 4 and 5 a deletion of three amino acids that are present in the sequence of all other sequenced clade B HIV-1 strains (consensus sequence RVKGIRKNYQHL). Representative clone SE18 was HLAB8 restricted, as it lysed three different B8-matched B-LCL (Table II), and the epitope fits the B8 motif (lysine at positions 3 and 5 and $\mathrm{COOH}$-terminal leucine) (47).

A CTL clone (LWF A5) from subject LWF recognized vaccinia vectors expressing the Env sequence of the BH10 molecular clone but not vectors expressing the Env sequence of the $\mathrm{BH} 8$ clone. The $\mathrm{BH} 10$ and $\mathrm{BH} 8$ molecular clones are both derived from the HIV-1 IIIB strain and differ in only 13 of the 863 amino acids (27). Using vaccinia vectors expressing serial deletions of the BH10 sequence (26), we predicted that the epitope was between amino acids 60 and 165 . However, overlapping synthetic peptides corresponding to the PV22 strain sequence and spanning that region were not recognized, even though BH10 and PV22 strains have no reported differences in their sequences in that region. Comparison of the BH10 to the $\mathrm{BH} 8$ sequence revealed that in this region the two clones differ only at position 165 (leucine for $\mathrm{BH} 8$, isoleucine for $\mathrm{BH} 10$ ). Although a synthetic 20-mer containing aa 156-175 was not recognized, the 10-mer NCSFNISTSI (aa 156-165), with the position 165 isoleucine at its $\mathrm{COOH}$ terminus efficiently sensitized autologous target cells. Interestingly, addition of even one residue (arginine) next to the $\mathrm{COOH}$-terminal isoleucine prevented recognition, explaining the lack of recognition for the 20-mer and the 25-mer PV22 synthetic peptides containing the epitope (data not shown). The epitope is also type-specific, as only one of 103 other HIV-1 clade B sequences contains a serine instead of threonine at position 163 (13), and the consensus clade B sequence with threonine at position 163 was not recognized by the LWF A5 clone (see below). Thus, the use of target cells expressing autologous viral gene products allowed mapping of this type-specific epitope that partially overlaps with the V2 hypervariable region of gp120.

CTL clone LWF A5 lysed four different B cell lines expressing both the B14 and Cw8 HLA molecules, which are in strong disequilibrium linkage (48). However, the H9 cells transfected with the B14 allele were not recognized (Table II), suggesting that the restricting HLA molecule was Cw8. Although the specific clone was able to efficiently lyse targets pulsed with the epitope at the concentration of $100 \mu \mathrm{g} / \mathrm{ml}$ (lysis $>90 \%$ ), the lowest concentration at which the epitope was able to sensitize autologous target cells was $10 \mu \mathrm{g} / \mathrm{ml}$.

\section{Effects of naturally occurring sequence variation on recognition} by CTL clones

To evaluate the effects of sequence variation shown by diverse HIV-1 strains on recognition by CTL clones, we synthesized peptides exhibiting amino acid substitutions corresponding to known clade B variants of these CTL epitopes derived from the Los Alamos Data Base. The majority of HIV-specific CTL clones were broadly cross-reactive with other clade B viruses, demonstrating recognition of virtually all the variant peptides at the highest concentration tested $(100 \mu \mathrm{g} / \mathrm{ml})$, although peptide titration assays revealed that peptides corresponding to the IIIB sequence achieved half-maximum lysis at the lowest concentration (Table III). Analysis of recognition of peptide variants for CTL clones specific for the epitope gp120/241-249 was not performed due to the limited ability to propagate these clones in culture. For epitopes p24/215-223, gp41/557-
565, and RT/231-238, even the substitution of $\mathrm{COOH}$-terminal anchor residues did not abrogate recognition. The only exception was for clones from subject LWF that recognize the epitope gp41/584-592, for which recognition of variant peptides has been previously reported (44). For this clone, variant peptides with single amino acid substitutions resulted in either abrogation of recognition or $>50 \%$ drop in lysis at the highest peptide concentration tested (44).

In contrast, CTL clones recognizing the type-specific RT/ 273-282 epitope and highly variable regions of gp120 were not able to recognize naturally occurring variants. To characterize the degree of variability of an epitope, we used the Kabat-Wu formula (49). As shown in Table IV, the most variable epitopes are the two type-specific Env epitopes gp120/2-10, and gp120/156-165. Synthetic peptides corresponding to naturally occurring variant sequences of these three epitopes were not able to sensitize target cells for lysis by the appropriate CTL clones (Table III). Thus, of the 11 CTL epitopes identified in these subjects, three were type specific in that these epitopes contained either unique or uncommon sequences and that CTL clones specific for these epitopes were unable to recognize sequences corresponding to any other clade B HIV-1 strain.

\section{Longitudinal analysis of HIV-1-specific CTL response}

To quantify and compare the CTL response in the three study subjects at different time points, limiting dilution PFA and bulk assays were used. For both methods, cryopreserved PBMC were stimulated using autologous B-LCL infected with a trivalent vaccinia vector expressing the HIV-1 gag, pol, and $e n v$, and subsequently inactivated using psoralen and UV light (32).

A broadening of the CTL response to recognize additional CTL epitopes was observed in subject LWF. Seroconversion for this subject was first documented in October 1985. Cryopreserved PBMC obtained from subject LWF at five different time points $(1986,1987,1989,1992$, and 1995) were stimulated and subsequently assessed for CTL activity using a panel of autologous B-LCL either infected with vaccinia vectors expressing autologous viral antigens or pulsed with peptides corresponding to the seven known CTL epitopes. As shown in

Table IV. Variability of CTL Epitopes

\begin{tabular}{lll}
\hline \multicolumn{1}{c}{ Epitope } & HLA & Variability* \\
\hline gp120/2-10 & B8 & 5.01 \\
gp120/156-165 & Cw8 & 3.51 \\
gp41/584-592 & B14 & 2.56 \\
gp41/557-565 & B51 & 2.21 \\
p17/77-85 & A2 & 1.9 \\
gp120/241-249 & Cw8 & 1.73 \\
p24/215-223 & B55 & 1.6 \\
RT231-238 & B51 & 1.49 \\
RT328-336 & B35 & 1.4 \\
RT/273-282 & B35 & 1.4 \\
p24/349-359 & A11 & 1.11 \\
& & \\
\hline
\end{tabular}

*Variability is expressed as the average variability per residue as calculated by the Kabat-Wu formula (49) (variability = number of different amino acids occurring at a given position/frequency of the most common amino acid at that position). 


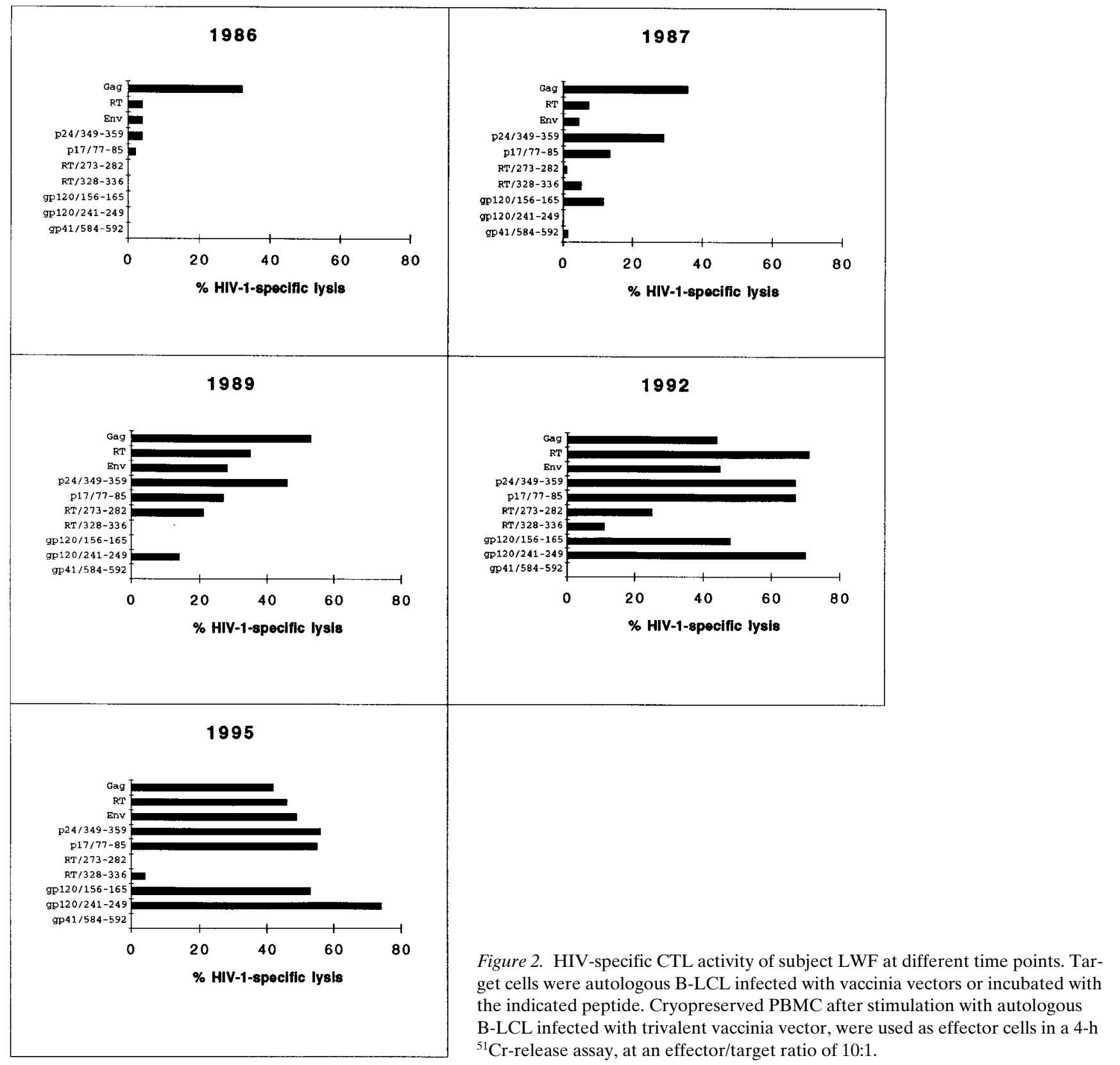

Fig. 2, in October 1986 the only HIV-1-specific CTL activity detected was against Gag, with no activity detected against specific epitopes, presumably reflecting Gag-specific activity directed against epitopes not identified using CTL clones. 5 mo later, in March 1987, CTL activity specific for two Gag epitopes, p24/349-359 and p17/77-85, was detected. In 1989, activity against all three HIV-1 antigens, Gag, RT, and Env, was detected, while two Gag, one RT, and one Env epitopes were recognized. PBMC obtained 3 yr later, in 1992, showed HIV-1-specific CTL activity against Gag, RT, Env, and all the identified epitopes except gp41/584-592, although specific lysis for the two RT epitopes was relatively lower. Finally, in 1995, Gag, RT, and Env antigens were recognized as well as two Gag and two Env epitopes. Broadening of the CTL response in subject LWF was confirmed using limiting dilution PFA (Table V). CTLp frequencies for Gag, RT, and Env antigens in a sample from 1986 were $\sim 30$-fold lower compared with the frequencies in 1990 and 1995. The use of cryopreserved PBMC raised the question whether the low CTL activity observed at the earliest time point tested might be the result of prolonged cryopreservation. To address this issue, we examined the EBV-specific CTL activity of cryopreserved PBMC from the same subject. Limiting dilution PFA revealed that the frequency of EBV-specific CTLp was 2,716 CTLp/106 PBMC in March 1987 and 529 CTLp/10 6 PBMC eight years later, in March 1995, suggesting that prolonged cryopreservation did not account for the low level of HIV-1-specific CTL activity observed.

The first HIV-positive sample for subject LWR was identified in August 1985, but the first available study sample was obtained from the donor in October 1992, when the CD4 $4^{+} \mathrm{T}$ cell count was only 10 cells $/ \mathrm{mm}^{3}$. Consistent with the advanced 
Table V. Frequency of HIV-1-specific CTL Precursors in Subject LWF at Three Different Time Points

\begin{tabular}{lcrr}
\hline & \multicolumn{3}{c}{ HIV-1-specific CTLp (CTLp/10 PBMC) } \\
\cline { 2 - 4 } & $10 / 86$ & $2 / 90$ & $3 / 95$ \\
\hline Gag & 8 & 244 & 122 \\
RT & 0 & 98 & 100 \\
Env & 3 & 96 & 86 \\
\hline
\end{tabular}

stage of the disease, only low levels of HIV-1-specific CTL activity were detected using PFA and bulk assays. In October 1992 the frequency of Gag-specific CTL precursors was 18 CTLp $/ 10^{6}$ cells, whereas no CTL precursors specific for RT, Env, or Nef antigens were detected. 27 mo later, in January 1995, both PFA and bulk assays revealed only a weak Gagspecific CTL activity (23 CTLp/10 cells and 30\% lysis, respectively), with no detectable recognition of RT or Env.

Subject LWS was infected in August 1990. As shown in Fig. 3, 1 mo later a strong Env-specific CTL response was present, and 6 mo later, in April 1991, strong CTL responses against Gag, RT, and Env were detected and epitope gp41/557-565 was recognized. The same CTL response against Gag, RT, and Env was observed in March 1992, although Env-specific activity declined. Several attempts to quantify these CTL responses using limiting dilution PFA failed because of poor cell growth or high background activity.

\section{Discussion}

Previous studies of CTL responses in HIV-1 infection have been hampered by the use of target cells expressing viral proteins from laboratory strains of HIV-1 that are likely to differ significantly from the viruses infecting study subjects. In this study we have used target cells expressing HIV-1 proteins derived from the IIIB strain to characterize the range of CTL epitopes recognized by three laboratory workers infected with HIV-1 IIIB. We characterized a total of $65 \mathrm{CD}^{+}$HLA classI-restricted CTL clones recognizing 11 different CTL epitopes lying in the Gag, RT, and Env proteins. Of these 11 epitopes, three were type specific, as defined by the failure of CTL clones specific for these epitopes to recognize any other clade $\mathrm{B}$ variant. These type-specific epitopes contained sequences that were either unique for HIV-1 IIIB (epitope gp120/2-10) or have been reported in only one other clade B sequence to date (epitopes gp120/156-165 and RT/273-282). Both typespecific Env epitopes lie in highly variable regions of the gp120 protein, while the other type-specific epitope lies in RT. These results suggest that type-specific CTL responses may be directed not only against the highly variable Env protein, but also against the more conserved HIV-1 proteins, a finding reflecting the significant sequence variation exhibited by HIV-1 as well as the ability of even single amino acid mutations within epitopes to abolish recognition by CTL. Based on the epitope specificity of T cell clones, CTL directed at type-specific epitopes appear to constitute a significant component of the overall response to $\mathrm{HIV}-1$ in these subjects. Although

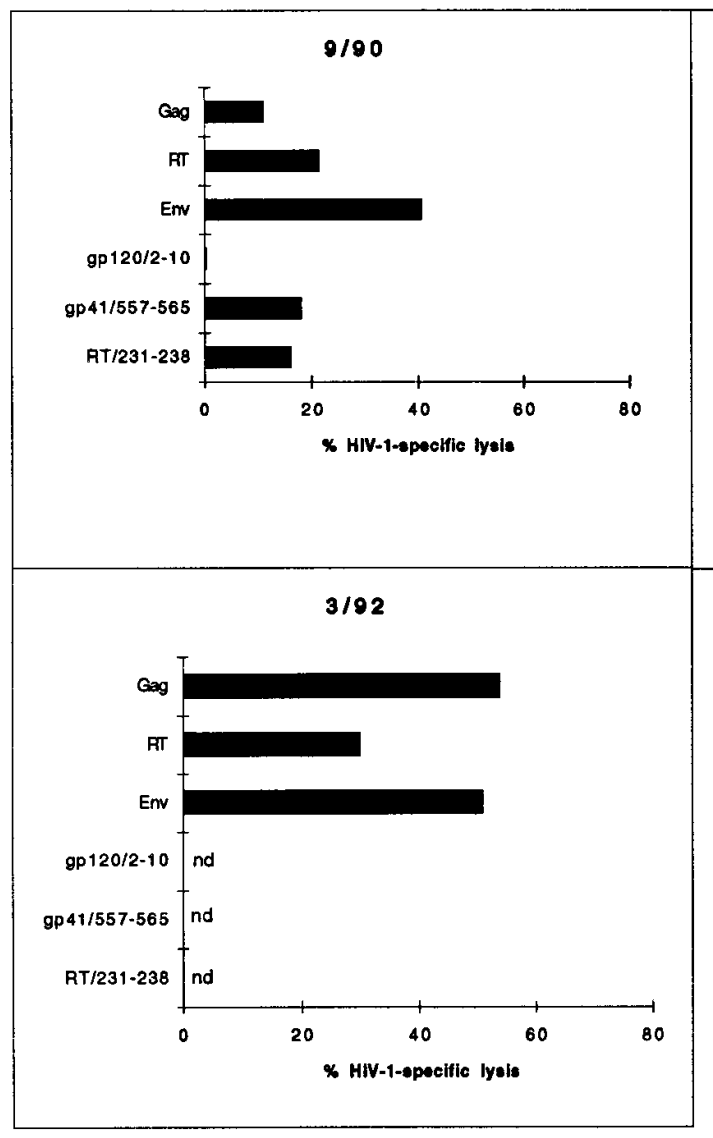

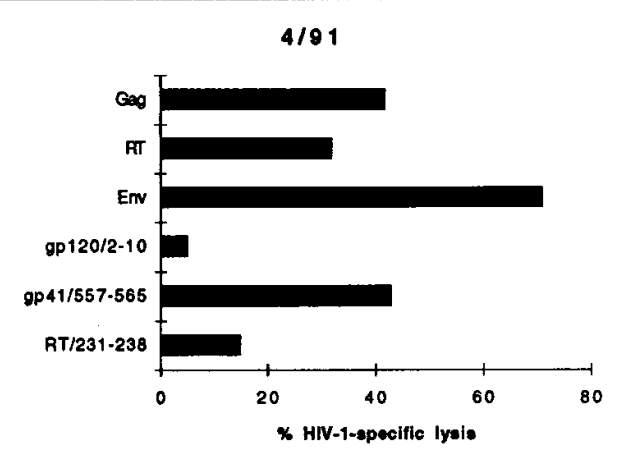

Figure 3. HIV-specific CTL activity of subject LWS at three different time points. Cryopreserved PBMC after stimulation with autologous B-LCL infected with trivalent vaccinia vector were incubated with target cells at effector/target ratio of 10:1. Target cells were autologous B-LCL infected with vaccinia vectors or incubated with indicated peptides. Epitopes were not known at the time the 3/92 sample was analyzed. 
analysis of CTL clones to characterize epitope specificity of bulk CTL responses may potentially be subject to sampling error, our assessment of the relative contribution of type-specific CTL responses is strengthened by isolation of multiple clones specific for these epitopes at more than one time point and by the recognition of these epitopes using bulk PBMC. Since type-specific CTL responses appear to make up a minority of the overall CTL response, use of heterologous targets is likely to significantly underestimate CTL responses against HIV-1, especially for highly variable regions of Env.

Longitudinal analysis of the fine specificity of CTL responses in subjects LWF and LWS showed striking differences in the evolution of these responses over time. For subject LWF, there was a broadening of the CTL response to recognize additional HIV-1 epitopes and viral proteins. Early after HIV infection, subject LWF showed low CTL activity against only Gag, and no recognition of known epitopes. The frequencies of CTLp were low or undetectable. Bulk and limiting dilution PFA at later time points revealed that CTL response became gradually broader, recognizing additional epitopes and the frequencies of Gag, RT, and Env-specific CTLp had also increased. The low level of HIV-specific CTL activity observed at early time points does not appear to be due to prolonged cryopreservation, as limiting dilution PFA revealed a high frequency of EBV-specific CTLp. In contrast, subject LWS has had a strong, polyclonal CTL response from the initial time point analyzed 1 mo after infection, and this CTL reponse was relatively maintained for at least $2 \mathrm{yr}$.

Despite an expanding number of publications on HIV-1-specific CTL, relatively little longitudinal information is available on recognition of specific epitopes. Most studies have examined recognition of HIV-1 proteins rather than specific epitopes (6), and those studies examining recognition of specific epitopes have generally provided cross-sectional rather than longitudinal data $(36,50-54)$. Consequently, little is known about the evolution of the fine specificity of the CTL response in HIV-1-infected subjects. To our knowledge, there is no prior demonstration of a broadening of the CTL response to recognize additional epitopes and proteins, although evolution of the CTL response to recognize variant CTL epitopes has been previously reported $(55,56)$. The progressive broadening of the CTL response observed in subject LWF observed over a 6-yr period suggests considerable plasticity in the CTL response to HIV-1 and that infected subjects can develop new responses to additional epitopes. The progressive increase in the number of CTL epitopes recognized may reflect either the effects of ongoing viral replication, the consequences of sequence variation in CTL epitopes, or some combination of the above. Analysis of the evolution of sequence variation in the CTL epitopes of these subjects will provide valuable information in this regard. Longitudinal analysis of the epitope specificity of additional HIV-1-infected individuals, preferably using target cells expressing homologous viral proteins, will be necessary to assess whether the broadening of the CTL response observed in subject LWF is a common finding.

Previous studies of these subjects revealed that for subjects LWF and LWS, temporal evolution of the antibody response was similar to that observed for CTL responses. Subject LWF had a slow rise in the level of all antibodies (anti-gp160, antiGag, neutralizing) between 1985 and 1989, and then levels remained constant until 1992 (17). Broadening of the neutralization response was observed $2.5 \mathrm{yr}$ after seroconversion, although HIV isolates showed little sequence divergence from IIIB during the 5-yr period after infection (16). In contrast, LWS had high levels of antibodies from the initial time point, and during 1992 a fall in the levels of anti-gp120, anti-V3, and neutralizing antibodies was observed. As mentioned above, a similar decline in Env-specific CTL response was observed in subject LWS at the same time point.

The differences between subjects LWF and LWS regarding the patterns of temporal evolution of humoral and cellular immune responses to HIV and the clinical course may be related to the size of the infecting inoculum and the initial viral load. Both subjects were healthy adults without other risk factors, infected by the same strain of HIV. Subject LWF, who was infected as the result of an exposure that was initially unrecognized, had a slow disease progression as $11 \mathrm{yr}$ after infection CD4 counts are still 190 cells $/ \mathrm{mm}^{3}$. Antibody and CTL responses were low initially, and then became gradually stronger and broader despite the lack of significant viral diversity. In contrast, based on the known exposure, LWS may have been infected with a relatively large inoculum, and has had more rapid disease progression as CD4 counts declined to 250 cells/ $\mathrm{mm}^{3}<5 \mathrm{yr}$ after infection. Humoral and cellular immune responses in this subject were strong from the initial time point but started declining rapidly.

For subjects LWF and LWS, a strong humoral and cellular immune response developed at earlier or later time points in the course of HIV infection did not prevent disease progression. Despite a strong polyclonal CTL response, subject LWF ultimately progressed to AIDS with CD4 counts dropping from 400 to 190 cells $/ \mathrm{mm}^{3}$ during the course of the study. Previous studies have arrived at contradictory conclusions regarding the role of a polyclonal CTL response. Using a mathematical model, Nowak et al. (56) have suggested that a heterogeneous viral population induces a fluctuating CTL response against multiple epitopes. An unexpected conclusion from this model was that CTL recognition of one or two epitopes may reflect a more effective control of viral replication. Another study in asymptomatic long-term nonprogressors showed that antigenic heterogeneity is not required for the generation of a polyclonal CTL response and broad and strong CTL responses may be associated with a lack of disease progression (5). In subject LWF, we observed a polyclonal CTL response directed against multiple epitopes. Although detailed information on sequence variation within CTL epitopes is not yet available, preliminary analysis of viral isolates from this subject (reference 16 and unpublished data) does not show variation in CTL epitopes, suggesting that polyclonal CTL responses may not reflect in vivo sequence variation.

The low levels of HIV-specific CTL activity and HIV-specific antibodies (17) observed in subject LWR may be attributed to the advanced stage of the disease, as all available samples were obtained while the patient had AIDS and CD4 counts $<50$ cells $/ \mathrm{mm}^{3}$. For subjects LWF and LWS, a decline of CTL activity and antibody levels was observed at later time points in the course of infection. These data confirm previous studies that showed a gradual decline in CTL activity at the final stages of the disease (8). In contrast, EBV-specific activity in subject LWF was relatively maintained over the period of study. These results are consistent with previous reports that despite the decline in HIV-specific CTL activity at later stages of the disease, EBV-specific CTLp are relatively maintained $(8,57)$. 
The new epitopes described in this report continue to expand our knowledge regarding the remarkable diversity of epitopes recognized by HIV-specific CTL. A previous study of the antibody response in the three laboratory workers identified five immunogenic regions in gp120 (aa 1-20, aa 142-153, aa 300-330, aa 425-450, and aa 480-510) and two in gp41 (aa 580-610 and aa 820-850) (17). Interestingly, two of the CTL epitopes we mapped (gp120/2-10 and gp41/584-592) are in these regions. Also of note is the fact that two epitopes (gp120/ 156-165 and gp120/241-249, both from LWF) contain potential N-linked glycosylation sites and cysteine residues. Whether the presence of a glyclosylation site or a cysteine residue accounts for the high $\mathrm{SD}_{50}$ (sensitizing dose $50 \%$ ) values observed for these epitopes is not yet clear. A previous analysis of recognition of a class I-restricted CTL epitope containing an N-linked glycosylation site found that a CTL clone preferentially recognized the unmodified peptide rather than the glycosylated form (58). Finally, epitope gp120/2-10 is an HLAB8-restricted, type-specific epitope lying in a high variable region of the signal sequence of gp120. To our knowledge, this is the first described class I-restricted epitope in the signal sequence of an HIV-1 protein, although CTL epitopes in the signal sequences of other viral proteins have been described $(59,60)$.

In summary, our analysis of CTL response to HIV-1 using target cells expressing autologous viral proteins suggests that type-specific CTL responses represent a significant minority of the overall CTL response and are directed primarily, but not solely, against variable regions of the envelope. In one subject, we observed a gradual broadening of the CTL response over time. Further studies using targets expressing autologous proteins are clearly necessary to characterize the full spectrum of CTL responses and understand the relationship between disease progression and antiviral immunity.

\section{Acknowledgments}

We especially extend our appreciation to the laboratory workers infected with HIV-1 who have generously participated in these ongoing studies. We also thank Drs. Pat Earl, Gail Mazzara, and Dennis Panicali for donations of recombinant vaccinia viruses, Dean Mann for HLA typing, Richard Koup for donation of peptides, Ofer Mandeldoim and Robert Siliciano for donation of cell lines, Ginga Coclough for dedicated assistance with clinical care, and Susan Coveney and Carolyn O'Toole for manuscript preparation.

This work was supported by Public Health Service grants AI 33327, AI 28568, and AI 30914 from the National Institute of Allergy and Infectious Disease, by grant 1FO5 TWO5222 from the Fogarty International Center, National Institutes of Health, and by a Burroughs Wellcome Fund/Infectious Disease Society of America Young Investigator Award to R.P. Johnson. Synthesis of peptides was carried out using a peptide synthesizer provided by a grant from the Pediatric AIDS Foundation. N.V. Sipsas was partly supported by the Hellenic Scholarships Foundation and R.P. Johnson was a scholar of the American Foundation of AIDS Research at the time this work was performed.

\section{References}

1. McMichael, A.J., and B.D. Walker. 1994. Cytotoxic T lymphocyte epitopes: implications for HIV vaccines. AIDS (Phila.). 8(Suppl. 1):S155-S173.

2. Koup, R.A., J.T. Safrit, Y. Cao, C.A. Andrews, G. McLeod, W. Borkowsky, C. Farthing, and D.D. Ho. 1994. Temporal association of cellular immune responses with the initial control of viremia in primary human immunodeficiency virus type 1 syndrome. J. Virol. 68:4650-4655.

3. Borrow, P., H. Lewicki, B.H. Hahn, G.M. Shaw, and M.B.A. Oldstone.
1994. Virus-specific CD8+ cytotoxic T-lymphocyte activity associated with control of viremia in primary human immunodeficiency virus type 1 infection. $J$. Virol. 68:6103-6110.

4. Yang, O.O., S. Kalams, M. Rosenzwieg, A. Trocha, M. Koziel, B.D. Walker, and R.P. Johnson. 1996. Efficient lysis of HIV-1 infected cells by cytotoxic T lymphocytes. J. Virol. 70:5799-5806.

4a. Yang, O.O., S.A. Kalams, A. Trocha, H. Cao, A. Luster, R.P. Johnson, and B.D. Walker. 1997. Suppression of HIV-1 replication by CD8+ cells: evidence for HLA class I-restricted trigering of cytolytic and non-cytolytic mechanisms. J. Virol. In press.

5. Harrer, T., E. Harrer, S.A. Kalams, P. Barbosa, A. Trocha, R.P. Johnson, T. Elbeik, M.B. Feinberg, S.P. Buchbinder, and B.D. Walker. 1996. Cytotoxic T lymphocytes in asymptomatic long-term nonprogressing HIV-1 infection. J. Immunol. 156:2616-2623.

6. Rinaldo, C., X.-L. Huang, Z. Fan, M. Ding, L. Beltz, L.A.D. Panicali, G. Mazzara, J. Liebmann, M. Cottrill, and P. Gupta. 1995. High levels of anti-human immunodeficiency virus type 1 (HIV-1) memory cytotoxic T-lymphocyte activity and low viral load are associated with lack of disease in HIV-1-infected long-term nonprogressors. J. Virol. 69:5838-5842.

7. Klein, M.R., and C.A. van Baalen. 1995. Kinetics of Gag-specific cytotoxic T lymphocyte responses during the clinical course of HIV-1 infection: a longitudinal analysis of rapid progressors and long-term asymptomatics. J. Exp. Med. 181:1356-1372.

8. Carmichael, A., X. Jin, P. Sissons, and L. Borysiewicz. 1993. Quantitative analysis of the human immunodeficiency virus type 1 (HIV-1)-specific cytotoxic T lymphocyte (CTL) response at different stages of HIV-1 infection: differential CTL responses to HIV-1 and Epstein-Barr virus in late disease. J. Exp. Med. 177:249-256.

9. Rowland-Jones, S., J. Sutton, K. Ariyoski, T. Dong, F. Gotch, S. McAdam, D. Whitby, S. Sabally, A. Gallimore, T. Corrah, M. Takiguchi, T. Schultz, A. McMichael, and H. Whittle. 1995. HIV-specific cytotoxic T-cells in HIV-exposed but uninfected Gambian women. Nat. Med. 1:59-64.

10. Pinto, L.A., J. Sullivan, J.A. Berzofsky, M. Clerici, H.A. Kessler, A.L. Landay, and G.M. Shearer. 1995. Env-specific cytotoxic T lymphocyte responses in HIV seronegative health care workers occupationally exposed to HIV-contaminated body fluids. J. Clin. Invest. 96:867-876.

11. Yap, K.L., G.L. Ada, and I.F. McKenzie. 1978. Transfer of specific cytotoxic $\mathrm{T}$ lymphocytes protects mice inoculated with influenza virus. Nature (Lond.). 273:238-239.

12. Byrne, J.A., and M.B. Oldstone. 1984. Biology of cloned cytotoxic T lymphocytes specific for lymphocytic choriomeningitis virus: clearance of virus in vivo. J. Virol. 51:682-686.

13. Myers, G., J.A. Berzofsky, B. Korber, R.F. Smith, and G.N. Pavlakis 1993. Human retroviruses and AIDS 1993: a compilation and analysis of nucleic acid and amino acid sequences. Los Alamos National Laboratory, Los Alamos, NM.

14. Johnson, R.P., A. Trocha, T.M. Buchanan, and B.D. Walker. 1993. Recognition of a highly conserved region of human immunodeficiency virus type 1 gp120 by an HLA-Cw4-restricted cytotoxic T-lymphocyte clone. J. Virol. 67: $438-445$.

15. Johnson, R.P., A. Trocha, T.M. Buchanan, and B.D. Walker. 1992. Identification of overlapping HLA class I-restricted cytotoxic T cell epitopes in a conserved region of the human immunodeficiency virus type 1 envelope glycoprotein: definition of minimum epitopes and analysis of the effects of sequence variation. J. Exp. Med. 175:961-971.

16. Reitz, M.S.J., L. Hall, M. Robert-Guroff, J. Lautenberger, B.H. Hahn, G.M. Shaw, L.I. Kong, S.H. Weiss, D. Waters, R.C. Gallo, and W. Blattner. 1994. Viral variability and serum antibody response in a laboratory worker infected with HIV type 1 (HTLV type IIIB). AIDS Res. Hum. Retroviruses. 10: 1143-1155.

17. Pincus, S.H., K.G. Messer, P.L. Nara, W.A. Blattner, G. Colclough, and M. Reitz. 1994. Temporal analysis of the antibody response to HIV envelope protein in HIV-infected laboratory workers. J. Clin. Invest. 93:2505-2513.

18. di Marzo Veroneze, F., M.S. Reitz, G. Gupta, M. Robert-Guroff, C. Boyer-Thompson, A. Louie, R.C. Gallo, and P. Lusso. 1993. Loss of a neutralizing epitope by a spontaneous point mutation in the V3 loop of HIV-1 isolated from an infected laboratory worker. J. Biol. Chem. 268:25894-25901.

19. Pincus, S.H., K.G. Messer, D.H. Schwartz, G.K. Lewis, B.S. Graham, W.A. Blattner, and G. Fisher. 1993. Differences in the antibody response to human immunodeficiency virus-1 envelope glycoprotein (gp120) in infected laboratory workers and vaccinees. J. Clin. Invest. 91:1987-1996.

20. Wain-Hobson, S., J.-P. Vartanian, M. Henry, N. Chenciner, R. Cheynier, S. Delassus, L. Pedroza Martins, M. Sala, M.-T. Nugeyre, D. Guetard, et al 1991. LAV revisited: origins of the early HIV-1 isolates from Institut Pasteur. Science (Wash. DC). 252:961-965.

21. Weiss, S.H., J.J. Goedert, S. Gartner, M. Popovic, D. Waters, P. Markham, F. Di Marzo Veroneze, M.H. Gail, E. Barkley, J. Gibbons, F.A. Gill, M. Leuther, G.M. Shaw, R.C. Gallo, and W.A. Blattner. 1988. Risk of human immunodeficiency virus (HIV-1) infection among laboratory workers. Science (Wash. DC). 239:68-71.

22. Centers for Disease Control and Prevention. 1992. 1993 Revised classification system for HIV infection and expanded surveillance of definition for 
AIDS among adolescents and adults. MMWR (Morb. Mortal. Wkly. Rep.). 41: $1-18$.

23. Walker, B.D., S. Chakrabarti, B. Moss, T.J. Paradis, T. Flynn, A.G. Durno, R.S. Blumberg, J.C. Kaplan, M.S. Hirsch, and R.T. Schooley. 1987. HIV-specific cytotoxic $\mathrm{T}$ lymphocytes in seropositive individuals. Nature (Lond.). 328:345-348.

24. Hammond, S.A., R.P. Johnson, S.A. Kalams, B.D. Walker, M. Takiguchi, J.T. Safrit, R.A. Koup, and R.F. Siliciano. 1995. An epitope-selective, transporter associated with antigen presentation (TAP)-1/2-independent pathway and a more general TAP-1/2-dependent antigen-processing pathway allow recognition of the HIV-1 envelope glycoprotein by CD8+ CTL. J. Immunol. 154: 6140-6156.

25. Bunce, M., and K. Welsh. 1994. Rapid DNA typing for HLA-C using sequence-specific primers (PCR-SSP): identification of serological and non-serologically defined HLA-C alleles including several new alleles. Tissue Antigens. 43:7-17.

26. Earl, P.L., S. Koenig, and B. Moss. 1991. Biological and immunological properties of human immunodeficiency virus type 1 envelope glycoprotein: analysis of proteins with truncations and deletions expressed by recombinant vaccinia viruses. J. Virol. 65:31-41.

27. Ratner, L., W. Haseltine, R. Patarca, J.K. Livak, B. Starcich, S.F. Josephs, E.R. Doran, J.A. Rafalski, E.A. Whitehorn, K. Baumeister, et al. 1985. Complete nucleotide sequence of the AIDS virus, HTLV-III. Nature (Lond.). 313:277-284

28. Koup, R.A., J.L. Sullivan, P.H. Levine, D. Brettler, A. Mahr, G. Mazzara, S. McKenzie, and D. Panicali. 1989. Detection of major histocompatibility complex class I-restricted, HIV-specific cytotoxic T lymphocytes in the blood of infected hemophiliacs. Blood. 73:1909-1914.

29. Chakrabarti, S., K. Brechling, and B. Moss. 1985. Vaccinia virus expression vector: coexpression of $\beta$-galactosidase provides visual screening of recombinant virus. Mol. Cell. Biol. 5:3403-3409.

30. Johnson, R.P., S.A. Hammond, A. Trocha, R.F. Siliciano, and B.D. Walker. 1994. Induction of a major histocompatibility complex class I-restricted cytotoxic T-lymphocyte response to a highly conserved region of human immunodeficiency virus type I (HIV-1) gp120 in seronegative humans immunized with a candidate HIV-1 vaccine. J. Virol. 68:3145-3153.

31. Walker, B.D., C. Flexner, T.J. Paradis, T.C. Fuller, M.S. Hirsch, R.T. Schooley, and B. Moss. 1988. HIV-1 reverse transcriptase is a target for cytotoxic T lymphocytes in infected individuals. Science (Wash. DC). 240:64-66.

32. Lubaki, M.N., M.A. Egan, R.F. Siliciano, K.J. Weinhold, and R.C. Bollinger. 1994. A novel method for detection and ex vivo expansion of HIV type 1-specific cytolytic T lymphocytes. AIDS Res. Hum. Retroviruses. 10:14271431.

33. Kalams, S.A., R.P. Johnson, A.K. Trocha, M.J. Dynan, H.S. Ngo, R.T. D'Aquila, J.T. Kurnick, and B.D. Walker. 1994. Longitudinal analysis of T cell receptor (TCR) gene usage by human immunodeficiency virus 1 envelope-specific cytotoxic T lymphocyte clones reveals a limited TCR repertoire. J. Exp. Med. 179:1261-1271.

34. Lefkovits, I., and H. Waldmann. 1979. Limiting dilution analysis of cells of the immune system. Cambridge University Press. Cambridge.

35. Wong, J.T., and R.B. Colvin. 1987. Bi-specific monoclonal antibodies: selective binding and complement fixation to cells that express two different surface antigens. J. Immunol. 139:1369-1374.

36. Johnson, R.P., A. Trocha, L. Yang, G.P. Mazzara, D.L. Panicali, T.M. Buchanan, and B.D. Walker. 1991. HIV-1 gag-specific cytotoxic T lymphocytes recognize multiple highly conserved epitopes. Fine specificity of the gag-specific response defined by using unstimulated peripheral blood mononuclear cells and cloned effector cells. J. Immunol. 147:1512-1521.

37. Walker, B.D., C. Flexner, L.K. Birch, L. Fisher, T.J. Paradis, A. Aldovini, R. Young, B. Moss, and R.T. Schooley. 1989. Long-term culture and fine specificity of human cytotoxic T-lymphocyte clones reactive with human immunodeficiency virus type 1. Proc. Natl. Acad. Sci. USA. 86:9514-9518.

38. Falk, K., O. Rotzsche, M. Tagiguchi, B. Grahovac, V. Gnau, S. Stevanovic, G. Jung, and H.-G. Rammensee. 1994. Peptide motifs of HLA-A1, -A11, -A31, and -A33 molecules. Immunogenetics. 40:238-241.

39. Kubo, R.T., A. Sette, H.M. Grey, E. Appella, K. Sakaguchi, N.-Z. Zhu, D. Arnott, N. Sherman, J. Shabanowitz, H. Michel, et al. 1994. Definition of specific peptide motifs for four major HLA-A alleles. J. Immunol. 152:39133924.

40. Tsomides, T.J., A. Aldovini, R.P. Johnson, B.D. Walker, R.A. Young, and H.N. Eisen. 1994. Naturally processed viral peptides recognized by cytotoxic $\mathrm{T}$ lymphocytes on cells chronically infected by human immunodeficiency virus type 1 (HIV-1). J. Exp. Med. 180:1283-1293.

41. Shiga, H., T. Shioda, H. Tomiyama, Y. Takamiya, S. Oka, S. Kimura, Y. Yamaguchi, T. Gojoubori, H.-G. Rammensee, K. Miwa, and M. Takiguchi. 1996. Identification of multiple HIV-1 cytotoxic T-cell epitopes presented by human leukocyte antigen B35 molecules. AIDS (Phila.). 10:1075-1083.
42. Harrer, E., T. Harrer, P. Barbosa, M. Feinberg, R.P. Johnson, S. Buchbinder, and B.D. Walker. 1996. Recognition of the highly conserved YMDD region in the human immunodeficiency virus type 1 reverse transcriptase by HLA-A2-restricted cytotoxic T lymphocytes from an asymptomatic long-term nonprogressor. J. Infect. Dis. 173:476-479.

43. Falk, K., O. Rotzschke, B. Grahovac, D. Schendel, S. Stevanovic, G. Jung, and H.G. Rammensee. 1993. Peptide motifs of HLA-B35 and -B37 molecules. Immunogenetics. 38:161-162.

44. Kalams, S.A., R.P. Johnson, M.J. Dynan, K.E. Hartman, T. Harrer, E. Harrer, A.K. Trocha, W.A. Blattner, S.P. Buchbinder, and B.D. Walker. 1996. $\mathrm{T}$ cell receptor usage and fine specificity of human immunodeficiency virus 1-specific cytotoxic $\mathrm{T}$ lymphocyte clones: analysis of quasispecies recognition reveals a dominant response directed against a minor in vivo variant. J. Exp. Med. 183:1669-1679.

45. Falk, K., O. Rotzschke, M. Takiguchi, V. Gnau, S. Stevanovic, G. Jung, and H.G. Rammensee. 1995. Peptide motifs of HLA-B51, -B52 and -B78 molecules, and implications for Behcet's disease. Int. Immunol. 7:223-228.

46. Kawaguchi, G., W.H. Hildebrand, M. Hiraiwa, S. Karaki, T. Nagao, N. Akiyama, S. Uchida, K. Kashiwase, T. Akaza, R.C. Williams, et al. 1992. Two subtypes of HLA-B51 differing by substitution at position 171 of the $\alpha 2$ helix. Immunogenetics. 37:57-63.

47. Sutton, J., S. Rowland-Jones, W. Rosenberg, D. Nixon, F. Gotch, X.M. Gao, N. Murray, A. Spoonas, P. Driscoll, M. Smith et al. 1993. A sequence pattern for peptides presented to cytotoxic T lymphocytes by HLA B8 revealed by analysis of epitopes and eluted peptides. Eur. J. Immunol. 23:447-453.

48. Terasaki, P.I. 1980. Histocombatibility testing 1980. Report of the Eighth International Histocombatibility Workshop. Los Angeles, CA. 504-505.

49. Kabat, E., T. Wu, and H. Bilofsky. 1979. National Institutes of Health, Publication No. 80-2008. US Department of Health, Education, and Welfare. Washington, DC

50. Buseyne, F., M. McChesney, F. Porrot, S. Kovarik, B. Guy, and Y. Riviere. 1993. Gag-specific cytotoxic T lymphocytes from HIV-1 infected individuals: gag epitopes are clustered in three regions of the p24 gag protein. J. $\mathrm{Vi}$ rol. 67:694-702.

51. Clerici, M., D.R. Lucey, R.A. Zajac, R.N. Boswell, H.M. Gebel, H. Takahashi, J.A. Berzofsky, and G.M. Shearer. 1991. Detection of cytotoxic T lymphocytes specific for synthetic peptides of gp160 in HIV-seropositive individuals. J. Immunol. 146:2214-2219.

52. Culmann, B., E. Gomard, M.P. Kieny, B. Guy, F. Dreyfus, A.G. Saimot, D. Sereni, D. Sicard, and J.P. Levy. 1991. Six epitopes reacting with human cytotoxic CD8 + T cells in the central region of the HIV-1 NEF protein. J. Immunol. $146: 1560-1565$.

53. Lieberman, J., J.A. Fabry, M.C Kuo, P Earl, B. Moss, and P.R. Skolnik. 1992. Cytotoxic T lymphocytes from HIV-1 seropositive individuals recognize immunodominant epitopes in gp160 and reverse transcriptase. J. Immunol. 148:2738-2747.

54. Nixon, D.F., A.R. Townsend, J.G. Elvin, C.R. Rizza, J. Gallwey, and A.J. McMichael. 1988. HIV-1 gag-specific cytotoxic T lymphocytes defined with recombinant vaccinia virus and synthetic peptides. Nature (Lond.). 336:484487.

55. Phillips, R.E., J.S. Rowland, D.F. Nixon, F.M. Gotch, J.P. Edwards, A.O. Ogunlesi, J.G. Elvin, J.A. Rothbard, C.R. Bangham, C.R. Rizza, and A.J. McMichael. 1991. Human immunodeficiency virus genetic variation that can escape cytotoxic T cell recognition. Nature (Lond.). 354:453-459.

56. Nowak, M., R.M. May, R.E. Phillips, S. Rowland-Jones, D.G. Lalloo, S McAdam, P. Klenerman, B. Koeppe, K. Sigmund, C.R.M. Bangham, and A.J. McMichael. 1995. Antigneic oscillations and shifting immunodominance in HIV-1 infections. Nature (Lond.). 375:606-611.

57. Gerretti, A.M., M.E.M. Dings, C.A.C.M. van Els, C.A. van Baalen, F.J. Wijnholds, J.C.C. Borleffs, and A.D.M.E. Osterhaus. 1996. Human immunodeficiency virus type 1 (HIV-1) and Epstein-Barr virus-specific cytotoxic T lymphocyte precursors exhibit different kinetics in HIV-1-infected persons. $J$. Infect. Dis. 174:34-45.

58. Ferris, R.L., C. Buck, S.A. Hammond, A.S. Woods, R.J. Cotter, M Takiguchi, Y. Igarashi, Y. Ichikawa, and R.F. Siliciano. 1996. Class I-restricted presentation of an HIV-1 gp41 epitope containing an N-linked glycosylation site. Implications for the mechanism of processing of viral envelope proteins. $J$. Immunol. 156:834-840.

59. Kondo, T., H. Uenishi, T. Shimizu, T. Hirama, M. Iwashiro, K. Kuribayashi, H. Tamamura, N. Fujii, R. Fujisawa, M. Miyazawa, and H. Yamagishi 1995. A single retroviral gag precursor signal peptide recognized by FBL-3 tumor-specific cytotoxic T lymphocytes. J. Virol. 69:6735-6741.

60. Hombach, J., H. Pircher, S. Tonegawa, and R.M. Zinkernagel. 1995. Strictly transporter of antigen presentation (TAP)-dependent presentation of an immunodominant cytotoxic T lymphocyte epitope in the signal sequence of a virus protein. J. Exp. Med. 182:1615-1619. 